\title{
ASPECTS OF POSTGRADUATE MEDICINE
}

\section{VIII-Postgraduate Medical Centres-Stoke Mandeville and Birmingham}

\author{
[From a SPECIAL CORRESPONDENT]
}

Previous articles about postgraduate medical centres* have emphasized that the Christ Church conference on postgraduate education in December 1962 led to an "explosion" in their development. In the Oxford region, for example, the Nuffield Foundation sponsored a number of pilot postgraduate centres at selected peripheral hospitals-at Northampton, Reading, and Aylesbury. As elsewhere, each centre has tended to develop a special character according to its own interests. Stoke Mandeville Hospital at Aylesbury has always been linked with two main interests-the world-famous Spinal Injuries Unit, and research particularly in the field of rheumatism-but in addition some activity in the field of postgraduate education, both continuing and vocational, had been in progress for some time before the Christ Church conference. The present academic programme has been steadily evolved under the present tutor since January 1962. In developing a postgraduate centre the opportunity was taken to draw these three strands together, by linking the centre with a research unit in which general practitioners can work alongside hospital doctors. This Nuffield Research Unit, which was opened in May $1964,{ }^{1}$ contains research laboratories on the ground floor, together with a library (mainly equipped from postgraduate funds) and rooms for the postgraduate medical tutor, the librarian, and postgraduate secretary on the first floor. Although the journal club meets over sandwiches with coffee or beer each Monday in the Nuffield Library, most of the formal postgraduate programme takes place in a clinical lecture room some distance from the Unit. Nevertheless, in practice this separation has not been found to produce any difficulty or disadvantages-and indeed the proposed building to house the new lecture theatre will also be separate from the research unit. This building will contain a lecture room housing 80 people, together with a commonroom and bar, and an appeal for money has recently been launched.

Another long-cherished hope at Stoke Mandeville is that it will be possible to build a residential block. For some time students from the Middlesex Hospital and elsewhere have been spending an "elective month" at the hospital, where they take part in the day-to-day work and attend the postgraduate lectures. It has always been difficult to find enough rooms for them to live in during this time, and a similar problem has been found with housing postgraduate workers who come to study at the Spinal Injuries Unit, many of whom are from overseas.

\section{Educational Programme}

The educational programme at Stoke Mandeville is widely based, aiming at including all branches of the profession-an aim which is underlined by the composition of its advisory committee, which comprises doctors from varying medical fields Hence, as elsewhere, the programme has fallen into three natural parts-continuing education, vocational training, and general-practitioner refresher courses. The first part, continu ing education, has included regular lectures, clinical demonstrations, pathological meetings, and a journal club. Hospital doctors have been generally enthusiastic about these meetings, and a high attendance rate has been kept up, while several local general practitioners are also regular participants.

The vocational training programme is intended mainly for hospital junior staff, being organized by the medical and surgical postgraduate tutcrs. In addition to the regular lectures and ward work for both the Membership and Fellowship

* See B.Mi.7, 1966, 2, 45. 103, 167, and 295. examinations there is a teaching programme in obstetrics and gynaecology. These courses have also been attended by doctors from neighbouring hospitals, and a considerable number of housemen and registrars have been successful in obtaining higher degrees. The third part of the postgraduate programme, refresher courses aimed specifically at general practitioners, includes a regular Thursday afternoon session lasting for three hours, which usually comprises two lectures-discussion sessions and a clinical demonstration. In addition twice a year intensive three-day refresher courses covering a variety of topics are held, and have proved very successful. Occasional week-end courses have been organized by the College of General Practitioners, and the British Medical Association have made use of the available accommodation for evening meetings.

Senior doctors at Stoke Mandeville Hospital had no doubts about the considerable benefits resulting from the activities of the postgraduate centre: One obvious advantage was that the successes gained in higher examinations had seemed to have encouraged junior doctors to apply for jobs there, so that their supply and quality had not dropped as had been reported by other peripheral hospitals. Less tangible, but no less important, was the enjoyment that most senior doctors seemed to obtain from either teaching or participating in the programme, and the way in which this complemented the existing research programme-even though all these obligations were added to an already heavy load of routine work.

\section{Future Prospects}

Programmes similar to this one-with individual, local variations-seem to be the most likely future pattern for postgraduate education in peripheral hospitals. Nevertheless, at present there are still two main problems to be solved. Firstly, there is that of the heavy demands which any programme makes on its participants. Whereas these schemes have so far worked because of individual enthusiasm, by itself the latter is unlikely to be able to keep the momentum going indefinitely, and certainly any increase in the scope or amount of the programme would seem to be ruled out. More and more workers in this field now feel that eventually the main participants, and particularly the postgraduate tutors, will have to be appointed with sessions specifically devoted for teaching.

The second problem is the actual number and distribution of the postgraduate centres themselves. The rise in the number of centres has been dramatic, but should every hospital aim at having one, much as every teaching hospital seems to aim at doing open heart surgery and haemodialysis ? Few would disagree that every hospital should hold its own regular clinical meetings and case conferences, for enormous benefits are obtained for comparatively little work. Many would doubt, on the other hand, the need for the existence of a formal postgraduate centre at every hospital, complete with Membership and Fellowship courses, and refresher courses for general practitioners. This state of affairs has certainly not yet arrived in Britain, and wasteful overlap between centres in nearby hospitals might apply only to a few, densely populated areas, particularly those of the great conurbations. One way of tackling the problem of duplication of effort would be to co-ordinate all the programmes in a single area. In this way one hospital would specialize in one subject, and another in a second. Such a system has now been in operation for some years in the Birmingham Region, and a high degree of co-ordination has already been achieved. 


\section{Integration in Birmingham}

Postgraduate, vocational, and continued educational activity in the Birmingham Region has been steadily developing and increasing over the past 12 years. Moreover, the greater interest and enthusiasm on the part of all concerned and the financial help provided by the Nuffield Provincial Hospitals Trust grant have quickened the tempo of expansion during the last quinquennium. The Region extends over the five West Midlands counties of Warwickshire, Worcestershire, Shropshire, Staffordshire, and Herefordshire. Its population is five million -a tenth of the population of Britain-and its area is 5,000 square miles. Within it there are the United Birmingham Hospitals, some 220 other hospitals administered by the Birmingham Regional Hospital Board, about 800 consultants, 1,000 junior hospital staff, 2,000 general practitioners, and 250 doctors in the public health service and industry. The University of Birmingham, through its Board of Graduate Studies, has always been responsible for arranging and administering postgraduate vocational and continued education for the whole Region-a tradition which has grown from its function of arranging Section 48 courses (that is, those qualifying for the grant from the Ministry of Health) and at the wish of the Regional Board. The University has appointed four regional hospital consultants as Area Directors of Postgraduate Medical Education. One is responsible for the whole of the Potteries; one for Wolverhampton, Dudley, and Stourbridge ; one for Coventry, Rugby, and Nuneaton; and one for Hereford and Herefordshire. In addition the University has appointed clinical tutors for most of the major general hospitals not covered by an area director, and a postgraduate clinical tutor in psychiatry for each major psychiatric unit.

The function of the area directors and clinical tutors includes providing a programme of postgraduate education for junior staff ; the provision of adequate library facilities ; the arrangement of clinical meetings, seminars, clinicopathological conferences and other educational facilities in their hospital or hospitals; and the provision of Section 48 coursest for general practitioners in their area. They work in the closest co-operation with the Director of the Board of Graduate Studies of the University, and all the advertisement and finance of their courses and other postgraduate activities are dealt with by the University.

\section{Courses for Higher Diplomas}

In the Birmingham Region vocational training and courses for higher diplomas are planned on a regional basis, and conducted almost exclusively in regional hospitals. Most are on a day or half-day release basis, an arrangement which interferes least with the service responsibilities of the junior hospital staff for which these facilities are chiefly provided. Thus there is one course each year for the first part of the D.P.M. and one course for the second part for the whole of the regicn. Similarly one course only is provided each year for the primary F.R.C.S., the primary F.F.A. R.C.S., the first part M.C.Path., the M.R.C.O.G., the D.A. and the first and second parts of the D.M.R.D. and D.M.R.T. The number of junior hospital staff in the Region reading for the M.R.C.P. and the final F.R.C.S. is too great to be accommodated on a single course, and hence there are two courses for the final F.R.C.S., three courses for the M.R.C.P.—and, in addition, two neurology courses each year. The hospitals at which such courses are held are decided largely by the interest and enthusiasm of the staff and the facilities available. Thus the M.R.C.O.G. course is held at Dudley Road Hospital, Birmingham, the neurology courses at the Midland Centre for

+ Courses which qualify for Postgraduate Training Allowances.
Neurosurgery and Neurology, the anaesthetic courses at East Birmingham Hospital, and the ophthalmological symposia at the Birmingham and Midland Eye Hospital.

Vocational training for general practice has to date been catered for by "rotating internships" for post-registration graduates and by the "trainee practitioner scheme"-but the University and the Regional Board are about to advertise a three-year scheme of training which will satisfy the conditions for the vocational training allowance. This will include six months as a paediatric house officer, six months as an obstetric house officer, a year's rotating internship to cover other specialties, an attachment to a medical officer of health, a special university course of instruction, and six months as a trainee practitioner in an urban practice and six months in a rural practice.

\section{Postgraduate Centres}

So far six postgraduate centres have been built in the Region and a further eight are in the course of construction or planning. Those already in use have proved an enormous educational stimulus to the hospital or group which they serve: nevertheless, hospitals not yet possessing this advantage are making an important contribution.

The officers of the Birmingham Regional Hospital Board have a particularly enlightened approach to postgraduate medical education and research. Among other things they offer six Sheldon Research Fellowships for those with higher qualifications who wish to devote one or more years to research within the Region; nine supernumerary registrarships for senior overseas graduates who wish to come to Regional hospitals for specialized postgraduate experience; six supernumerary senior house officer appointments in orthopaedics for overseas graduates; and six supernumerary registrarships for those wishing to take the University of Birmingham D.M.R.D. course. In addition about one-third of the general practitioners in the Region have a hospital appointment-an arrangement which has proved of enormous continued educational value to the doctors concerned and an invaluable help to the hospital service.

\section{Reasons for Success}

Nobody would pretend that the pattern of postgraduate medical education established at Birmingham should necessarily be slavishly followed elsewhere in Britain. Nevertheless, the system is one that has been shown to work successfully over a large area, in hospitals that have more than their average share of present-day problems. The success of the postgraduate scheme may be ascribed to two main factors. Firstly, Birmingham seems to have arrived at a strong, yet fiexible pattern of administration, with its postgraduate dean and a committee containing representatives from all fields concerned. The second is the realization that high standards of medical treatment are closely linked to standards of medical education, both vocational and continuing, and that the schemes for the latter are expensive to carry out. Thus every year the Regional Board spends $£ 100,000$ on postgraduate education, and the hospital management committees $£ 15,000$ on medical libraries. In fact Birmingham seems to have put into practice J. R. Ellis's dictum, that "The dependence of the standard of medical care upon postgraduate training and continuing education mokes the provision of the necessary facilities for both as important a part of the health service as the provision of wards, outpatient clinics, operating theatres and health centres." 